\title{
Online Health Survey on Epileptic Children during Coronavirus Disease-2019 Pandemic
}

\author{
Ashraf Azmy ${ }^{1}$ D, Eman Mones Abushady ${ }^{2}$ D, Mones M Abu Shady ${ }^{1}$ (D) \\ ${ }^{1}$ Department of Child Health, Medical Research Division, National Research Centre, Cairo, Egypt; ${ }^{2}$ Department of Neurology, \\ Faculty of Medicine, Ain Shams University, Cairo, Egypt
}

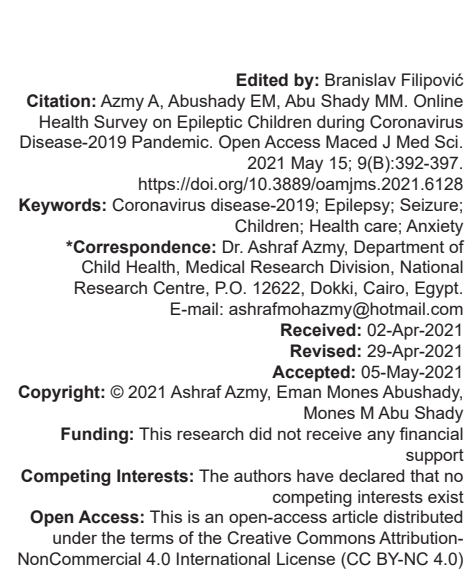

\section{Introduction}

Coronavirus disease 2019 (COVID-19) is a novel infectious disease caused by severe acute respiratory syndrome coronavirus 2 (SARS CoV-2), and the outbreak, which initially occurred in Wuhan, China, in late 2019 , is now rapidly spreading globally [1].

COVID-19 changed the world within a matter of weeks. The primary action to constrain the spread of the virus is public distancing. The current administrative measures of lock-down, social distancing, and selfisolation are intended at reducing the spread of the

\begin{abstract}
BACKGROUND: Coronavirus disease 2019 (COVID-19) is a novel infectious disease caused by severe acute respiratory syndrome coronavirus 2 , and the outbreak is now rapidly spreading globally. The current administrative measures of lock-down, social distancing, and self-isolation are intended at reducing the spread of the viral infection, management of children with neurological illnesses by instigating or worsening concomitant anxiety and depression, hindering the interactions with physicians, and leading to shortages or inconsistent supply of medicines. epilepsy during COVID-19 pandemic and provide the best possible care for those children while avoiding visits to

METHODS: The current study was an observational cross-section survey study. One hundred twenty children with owing in the epilepsy clinic of Medical Research Center of Excellence, and epilepsy clinic at Neurology Department, Faculty of Medicine, Ain Shams University aged above 4 years were recruited. The authors designed a 22-items questionnaire to address impact of COVID-19 crisis on the care, seizure outcome, behavior of children, and with mean age $8.34 \pm 3.877$ years. Before COVID pandemic, $18.3 \%$ of care providers had worries about epilepsy, while during the pandemic, $78.3 \%$ of them had the same worries. Twenty percent of the studied patients showed worsened sleep during the pandemic. Medical follow-up difficulties and drug access difficulties were found in $18.3 \%$ and $50 \%$ of the patients, respectively, during the pandemic. Child anxiety was $20 \%$ before the pandemic and $97.5 \%$ during the pandemic. Of the care providers, $95.8 \%$ were worried about their children of getting COVID 19. Thirty percent showed a need for psychological support, $76.7 \%$ for medical support, and $75 \%$ for information support about epilepsy. Medical support by phone or online during the pandemic was accepted by $80.8 \%$ of the caregivers. $>12$ years. All children without anxiety before the COVID-19 pandemic had anxiety during COVID-19 pandemic, while $87.5 \%$ of those with anxiety before COVID still had anxiety during the pandemic, signifying that COVID 19 pandemic increased the anxiety of the epileptic children significantly.
\end{abstract}

CONCLUSION: The present study found no increase in seizure exacerbation during the outbreak of COVID-19. During the pandemic, worries of the care providers about progression of the frequency of seizure and epileptic information as much as possible at home to keep children with epilepsy in good psychological and mental status as well as minimizing of risk of seizure exacerbation through adherence. Effective telemedicine tools will prove usefu for the long-term management of these patients. viral infection, minimizing contacts between potentially infected individuals and healthy subjects. However, they can complicate the management of children with neurological illnesses by instigating or worsening concomitant anxiety and depression, hindering the interactions with physicians, and leading to shortages or inconsistent supply of medicines [2].

Given this public health principle and the shortage of personal protective equipment during the global pandemic, all health care stakeholders need to reassess the feasibility for face-to-face health care encounters in providing patient care. The COVID-19 crisis inspired policymakers, regulators, and payers to encourage extended use of remote health care [3]. 
A stronger sense of community and ongoing propagation and implementation of telehealth facilities may improve population health, patient care, and lower expenses [4]. Telemedicine permits consultations with doctors without exposure to crowded situations and thus prevents the blowout of COVID-19 among patients [5].

Regarding the medical worries for epileptic children during COVID-19 pandemic, some clinicians proposed to inform patients that they should not cease antiepileptic drugs without the advice of a physician, even if it would affect the immune systems. Anxiety and depression in children and teenagers with epilepsy are common comorbidities which set a significant burden on patients and families and confound the clinical management of epilepsy during the pandemic [6].

Visits to doctors and periodic filling of prescriptions account for considerable challenge by parents of epileptic children during COVID-19 pandemic, in avoiding crowded situations. Going to emergency rooms because of increased or uncontrollable seizures could also expose the patient to infection with coronavirus, triggering anxiety, and fear for parents. The effect of COVID-19 pandemic on children with epilepsy may be negative to their psychological wellbeing and their seizure outcome.

The current study aims to provide information on the impact of the COVID-19 pandemic on the medical care and wellbeing of children with epilepsy, provide recommendations on how to minimize risk factors, and provide the best possible care for those children while avoiding visits to urgent care facilities and hospitalizations during the pandemic.

\section{Patients and Methods}

The current study was an observational crosssection survey study. One hundred twenty children with epilepsy following in the epilepsy clinic of Medical Research Center of Excellence and epilepsy clinic at Neurology Department, Faculty of Medicine, Ain Shams University aged above 4 years during the period from May 2020 to November 2020 were selected. They were recruited by extracting their contact information from their medical files. Twenty-two-item questionnaire was designed by the authors to address the impact of COVID-19 crisis on the care, seizure outcome, behavior of children, and concerns of their parents. It was sent to parents through email or WhatsApp online applications. The filling of questionnaire is supposed to take $10 \mathrm{~min}$ and was introduced in Arabic language with clear phrasing to parents of epileptic children. Consent form was sent to parents with the questionnaire to getting their approval to share in the survey. The patient's entire recorded data was highly confidential by investigators.

\section{Data availability statement}

Anonymized data will be shared by request from any qualified investigator.

\section{Statistics}

Data were filled in excel forms, tabulated, and finally were processed using Statistical Package for the Social Sciences version 21 for Windows (IBM Corp., Armonk, NY, USA).

Ages of the epileptic children were expressed as mean \pm standard deviation, minimum, and maximum. Categorical data were expressed as frequencies and percentages and were analyzed with the two-tailed Pearson Chi-square test. Odds ratio and $95 \%$ confidence interval were used to find the risk of residence on the worries of the caregivers. $p<0.05$ was accepted as statistically significant.

\section{Results}

The study included 120 epileptic children, 47 males and 73 females, with age ranged from 4 to 17 years with mean age $8.34 \pm 3.877$ years. Table 1 showed the frequency and the percentage of all the variables. Before the pandemic, $30 \%$ of the patients had seizure frequency weekly and less than weekly. During the pandemic, $27.5 \%$ had the same seizure frequency. As regard to medication, $84.2 \%$ continue the same medication, $2.5 \%$ stopped medication, and $13.3 \%$ needed more medication. Before COVID pandemic, $18.3 \%$ of care providers had worries about epilepsy (ER admission, getting medication, child mental health, family income status, family members affection), while during the pandemic, $78.3 \%$ of them had the same worries. Twenty percent of the studied patients showed worsened sleep during the pandemic. Medical follow-up difficulties and drug access difficulties were found in $18.3 \%$ and $50 \%$ of the patients, respectively, during the pandemic. Child anxiety was $20 \%$ before the pandemic and $97.5 \%$ during the pandemic. Of the care providers, $95.8 \%$ were worried about their children of getting COVID-19. Thirty percent showed a need for psychological support, $76.7 \%$ for medical support, and $75 \%$ for information support about epilepsy. Medical support by phone or online during the pandemic was accepted by $80.8 \%$ of the caregivers.

The study also showed that epileptic children with age $\leq 12$ years needed more psychological support than those $>12$ years $(p<0.05)$ (Table 2). Caregivers of epileptic children $\leq 12$ years were more worried about their children of getting COVID-19 than those $>12$ years old $(p<0.05)$ (Table 3$)$. Rural care providers were 3 times more at risk of having worries about COVID 19 


\section{Table 1: Frequency table of all variables}

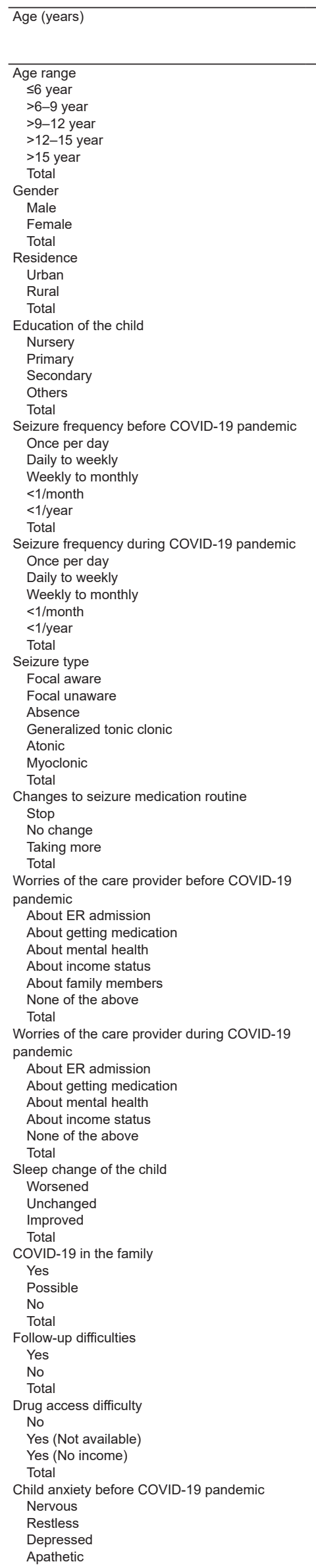

Table 1: (Continued)

\begin{tabular}{|c|c|c|}
\hline \multirow[t]{2}{*}{ Age (years) } & \multirow{2}{*}{$\begin{array}{l}\text { Mean }=8.34(\text { minimum } \\
=4, \text { maximum }=17) \\
\text { Frequency }\end{array}$} & \multirow{2}{*}{$\begin{array}{l}\text { SD }=3.877 \\
\text { Percent }\end{array}$} \\
\hline & & \\
\hline NA & 96 & 80.0 \\
\hline Total & 120 & 100.0 \\
\hline \multicolumn{3}{|c|}{ Child anxiety level before COVID-19 pandemic } \\
\hline Most of the time & 20 & 16.7 \\
\hline Some of the time & 7 & 5.8 \\
\hline None of the time & 93 & 77.5 \\
\hline Total & 120 & 100.0 \\
\hline \multicolumn{3}{|c|}{ Child anxiety during COVID-19 pandemic } \\
\hline Nervous & 50 & 41.7 \\
\hline Restless & 53 & 44.2 \\
\hline Depressed & 6 & 5.0 \\
\hline Effortless & 8 & 6.7 \\
\hline NA & 3 & 2.5 \\
\hline Total & 120 & 100.0 \\
\hline \multicolumn{3}{|c|}{ Child anxiety level during COVID-19 pandemic } \\
\hline Most of the time & 23 & 19.2 \\
\hline Some of the time & 78 & 65.0 \\
\hline A little of the time & 16 & 13.3 \\
\hline None of the time & 3 & 2.5 \\
\hline Total & 120 & 100.0 \\
\hline \multicolumn{3}{|c|}{ Worry about their child getting COVID-19 } \\
\hline A lot & 100 & 83.3 \\
\hline A little & 15 & 12.5 \\
\hline No & 5 & 4.2 \\
\hline Total & 120 & 100.0 \\
\hline \multicolumn{3}{|c|}{ Parent anxiety about social life } \\
\hline A lot & 42 & 35.0 \\
\hline A little & 31 & 25.8 \\
\hline No & 47 & 39.2 \\
\hline Total & 120 & 100.0 \\
\hline \multicolumn{3}{|c|}{ Parent anxiety about seizure worsening } \\
\hline A lot & 100 & 83.3 \\
\hline A little & 17 & 14.2 \\
\hline No & 3 & 2.5 \\
\hline Total & 120 & 100.0 \\
\hline \multicolumn{3}{|c|}{ Parent anxiety about financial matters } \\
\hline A lot & 28 & 23.3 \\
\hline A little & 33 & 27.5 \\
\hline No & 59 & 49.2 \\
\hline Total & 120 & 100.0 \\
\hline \multicolumn{3}{|c|}{ Parent anxiety about lifestyle } \\
\hline A lot & 23 & 19.2 \\
\hline A little & 31 & 25.8 \\
\hline No & 66 & 55.0 \\
\hline Total & 120 & 100.0 \\
\hline \multicolumn{3}{|c|}{ Psychological support needed } \\
\hline Yes & 36 & 30.0 \\
\hline No & 84 & 70.0 \\
\hline Total & 120 & 100.0 \\
\hline \multicolumn{3}{|l|}{ Medication support } \\
\hline Yes & 92 & 76.7 \\
\hline No & 28 & 23.3 \\
\hline Total & 120 & 100.0 \\
\hline \multicolumn{3}{|c|}{ Alarm support about seizures } \\
\hline Yes & 63 & 52.5 \\
\hline No & 57 & 47.5 \\
\hline Total & 120 & 100.0 \\
\hline Medical support (by $\mathrm{p}$ & & \\
\hline Yes & 97 & 80.8 \\
\hline No & 23 & 19.2 \\
\hline Total & 120 & 100.0 \\
\hline Information support a & & \\
\hline CovID-19 & & \\
\hline Yes & 90 & 75.0 \\
\hline No & 30 & 25.0 \\
\hline Total & 120 & 100.0 \\
\hline
\end{tabular}

pandemics than those of urban care providers $(p<0.05)$ (Table 4).

Table 2: Association between age group of epileptic children and psychological support needed

\begin{tabular}{llll}
\hline Age group & \multicolumn{2}{l}{ Psychological support needed } & Total \\
\cline { 2 - 3 } & Yes & No & \\
\hline$\leq 12$ years & 36 & 65 & 101 \\
$\quad \begin{array}{l}\text { Count } \\
\% \text { within age group }\end{array}$ & $35.6 \%$ & $64.4 \%$ & $100.0 \%$ \\
$>12$ years & & 19 & 19 \\
$\quad \begin{array}{l}\text { Count } \\
\% \text { within age group }\end{array}$ & $0.0 \%$ & $100.0 \%$ & $100.0 \%$ \\
\hline \multicolumn{2}{l}{ Pearson Chi-square $=9.68 .{ }^{*} \mathrm{p}=0.002}$. & &
\end{tabular}

In Table 5, $77.8 \%$ of children with seizure frequency daily and weekly before COVID-19 pandemic still had the same frequency during the pandemic; and 
$94 \%$ of those with seizure frequency monthly and yearly before the pandemic still also had the same frequency during the pandemic $(p<0.005)$. This finding denotes no effect of COVID-19 pandemic on seizure frequency on the studied group.

Table 3: Association between age group of epileptic children and worries about child getting COVID-19

\begin{tabular}{|c|c|c|c|}
\hline \multirow[t]{2}{*}{ Age group } & \multicolumn{2}{|c|}{ Worries about their child getting COVID-19 } & \multirow[t]{2}{*}{ Total } \\
\hline & Worried & Not worried & \\
\hline \multicolumn{4}{|l|}{$\leq 12$ years } \\
\hline Count & 101 & 0 & 101 \\
\hline$\%$ within age group & $100.0 \%$ & $0.0 \%$ & $100.0 \%$ \\
\hline \multicolumn{4}{|l|}{$>12$ years } \\
\hline Count & 14 & 5 & 19 \\
\hline$\%$ within age group & $73.7 \%$ & $26.3 \%$ & $100.0 \%$ \\
\hline
\end{tabular}

All caregivers with worries before the COVID19 pandemic still had worries during the pandemic, while $73.5 \%$ of those without worries before the pandemic had worries during the pandemic $(p<0.05)$, denoting that care provider worries increased significantly during the COVID-19 pandemic (Table 6).

Table 4: Association between COVID-19 pandemic worries of care providers and residence

\begin{tabular}{llll}
\hline Residence & \multicolumn{2}{l}{ Worries of the care provider during the pandemic } & Total \\
\cline { 2 - 3 } & Worries & No worries & \\
\hline Rural & & 8 & 63 \\
$\quad$ Count & 55 & $12.7 \%$ & $100.0 \%$ \\
$\quad$ \% within residence 2 & $87.3 \%$ & 18 & 57 \\
$\begin{array}{l}\text { Urban } \\
\quad \text { Count }\end{array}$ & 39 & $31.6 \%$ & $100.0 \%$ \\
$\quad \%$ within residence 2 & $68.4 \%$ & & \\
\hline OR $=3.137 .95 \% \mathrm{Cl} \mathrm{1.25-8.03.}{ }^{*} \mathrm{p}=0.015$ &
\end{tabular}

All children without anxiety before COVID-19 pandemic had anxiety during COVID-19 pandemic, while $87.5 \%$ of those with anxiety before COVID still had anxiety during the pandemic $(p<0.000)$, signifying that COVID-19 pandemic increased the anxiety of the epileptic children significantly (Table 7).

Table 5: Association between seizure frequency and COVID-19 pandemic in epileptic children

\begin{tabular}{|c|c|c|c|}
\hline \multirow[t]{2}{*}{$\begin{array}{l}\text { Seizure frequency before } \\
\text { COVID-19 pandemic }\end{array}$} & \multicolumn{2}{|c|}{$\begin{array}{l}\text { Seizure frequency during COVID- } \\
19 \text { pandemic }\end{array}$} & \multirow[t]{2}{*}{ Total } \\
\hline & Weekly and less & $>$ Weekly & \\
\hline \multicolumn{4}{|l|}{ Weekly and less } \\
\hline Count & 28 & 8 & 36 \\
\hline $\begin{array}{l}\% \text { within seizure frequency } \\
\text { before COVID-19 pandemic }\end{array}$ & $77.8 \%$ & $22.2 \%$ & $100.0 \%$ \\
\hline \multicolumn{4}{|l|}{ >Weekly } \\
\hline Count & 5 & 79 & 84 \\
\hline $\begin{array}{l}\% \text { within seizure frequency } \\
\text { before COVID-19 pandemic }\end{array}$ & $6.0 \%$ & $94.0 \%$ & $100.0 \%$ \\
\hline
\end{tabular}

\section{Discussion}

With about 50 million people affected worldwide, epilepsy is one of the most common neurological diseases globally and an important cause of disability and mortality [7] deeply affecting the quality of life and social and academic aspects, requiring long-term management [8]. At the end of 2019, an outbreak of COVID-19 caused by the novel coronavirus (SARS CoV-2) emerged in Wuhan, Hubei Province,
China and has rapidly spread throughout the country and the rest of the world. Almost 2 months later, the World Health Organization declared the coronavirus outbreak a pandemic and predicted that the virus would likely spread to all countries on the globe [9].

Table 6: Association between worries of the caregiver and COVID-19 pandemic in epileptic children

\begin{tabular}{llll}
\hline \multirow{2}{*}{$\begin{array}{l}\text { Worries of the care provider } \\
\text { before the pandemic }\end{array}$} & \multicolumn{2}{l}{$\begin{array}{l}\text { Worries of the care provider } \\
\text { during the pandemic }\end{array}$} & \\
\cline { 2 - 3 } & Worries & No worries & \\
\cline { 2 - 3 } $\begin{array}{l}\text { Worries } \\
\quad \begin{array}{lll}\text { Count } \\
\% \text { within worries of the care provider }\end{array}\end{array}$ & 22 & 0 & 22 \\
$\begin{array}{l}\text { about COVID-19 before the pandemic } \\
\text { No worries }\end{array}$ & & $0.0 \%$ & $100.0 \%$ \\
$\begin{array}{l}\text { Count } \\
\text { \% within worries of the care provider } \\
\text { about COVID-19 before the pandemic }\end{array}$ & 72 & & \\
\hline
\end{tabular}

Regular outpatient consultations are therefore important for optimizing antiseizure therapy, managing epilepsy-related behavioral or psychological problems, treating concomitant neurological disorders, and conveying psychological support. All these activities can be severely hampered by the containment measures established to face the pandemic (social distancing, quarantine, and isolation). Telemedicine services can prove extremely useful in supporting re-mote healthcare in persons with epilepsy during the current COVID-19 pandemic, particularly for their role in facilitating the interactive exchange of information between patients and physicians [9], [10], [11].

Table 7: Association between child anxiety and COVID-19 pandemic in epileptic children

\begin{tabular}{llll}
\hline $\begin{array}{l}\text { Child anxiety before COVID- } \\
19 \text { pandemic }\end{array}$ & \multicolumn{2}{l}{$\begin{array}{l}\text { Child anxiety during COVID } \\
\text { pandemic }\end{array}$} & \\
\cline { 2 - 3 } & With anxiety & No anxiety & \\
\hline $\begin{array}{l}\text { With anxiety } \\
\quad \text { Count } \\
\% \text { within Child anxiety }\end{array}$ & 21 & 3 & 24 \\
$\quad \begin{array}{l}\text { before COVID-19 pandemic } \\
\text { No anxiety }\end{array}$ & $87.5 \%$ & $12.5 \%$ & $100.0 \%$ \\
$\quad \begin{array}{l}\text { Count } \\
\% \text { within Child anxiety }\end{array}$ & 96 & 0 & \\
$\quad$ before COVID-19 pandemic & $100.0 \%$ & $0.0 \%$ & $100.0 \%$ \\
\hline Pearson Chi-square $=12.31 .{ }^{*} \mathrm{p}=0.000$. & & & \\
\hline
\end{tabular}

In the current study, seizure frequency before COVID-19 pandemic was not significantly different from the frequency after the pandemic. However, care providers' worries about progression of the frequency of seizure before COVID-19 pandemic increased significantly during the pandemic. Anxiety of the epileptic children increased significantly during COVID-19 pandemic compared to that before the pandemic.

In a single-center, cross-sectional study in China, 362 people with epilepsy were surveyed via online questionnaires between February 23 and March 5, 2020. Atotal of 31 (8.56\%) patients had increased seizures during the outbreak. Exposure history to COVID-19, uncontrolled seizure after therapy, seizure frequency of 2 or more times/month before the outbreak, and worry about the adverse effect of the outbreak on overall seizure-related issues were risk factors for increased seizures [12].

A cross-sectional study including 255 epileptic patients assessed by telephone contact in an epilepsy clinic 
during the first month of confinement in Spain was done. Demographic and clinical characteristics were recorded and a 19-item questionnaire was systematically completed. An increase in seizure frequency was reported by $9.8 \%$ patients, $26.7 \%$ patients reported with anxiety, $8.6 \%$ with depression, $12.2 \%$ with both, and $28.2 \%$ with insomnia, $28.6 \%$ patients with reduction in economic income. Insomnia, fear of epilepsy, and income reduction were associated with a higher risk of increased seizure frequency [13].

An online questionnaire was sent to patients from outpatient clinic, a reference center in Spain for drug-resistant epilepsy, inquiring about the effects of lockdown due to COVID-19 pandemic, from March to May 2020. Of 627 patients, $56 \%$ had seizure frequency as usual, while $31.2 \%$ reported an increased infrequency. Half reported anxiety or depression, and $25 \%$ increased behavioral disorders. In agreement with the current study, the investigators concluded that seizure frequency and severity remained unchanged in most patients during the lockdown [14].

A cross-sectional case-control study examined a consecutive sample of patients $>15$ years (252 epileptic patients) treated at the epilepsy center of West China Hospital between February 1 and February 29, 2020. As controls, sex- and age-matched healthy visitors of inpatients (252) were also enrolled during the same period. Data on demographics and attention paid to COVID-19 were collected by online questionnaire. Patients with epilepsy had significantly higher scores of psychological distresses than healthy controls, including feeling nervous, hopeless, restless, or fidgety. Diagnosis of drug-resistant epilepsy and time spent following media reports of the COVID-19 outbreak was significantly associated with severe psychological distress [15].

Members of the American Epilepsy Society (337) were surveyed between April 30 and June 14, 2020, for the impact of COVID-19 pandemic. About a third (30\%) of respondents stated that they had patients with COVID-19 and reported no significant change in seizure frequency. The majority of respondents felt that there were at least some barriers for people with epilepsy in receiving appropriate clinical care. Medication shortages were noted by approximately $30 \%$ of respondents. Telehealth was overwhelmingly found to have value [16], [17].

However, the current study has some limitations. First, it is a cross-sectional study, which only allows for the association but not causation. Second, discrepancy of individual seizure frequency from month to month may affect the frequency of seizure during the months of the outbreak of COVID-19.

\section{Conclusion}

The present study found no increase in seizure exacerbation during the outbreak of COVID-19. During the pandemic, worries of the care providers about the progression of the frequency of seizure and epileptic children anxiety increased significantly. Physicians should offer health care facilities including medications and information as much as possible at home to keep children with epilepsy in good psychological and mental status as well as minimizing of risk of seizure exacerbation through adherence. Effective telemedicine tools will prove useful for the long-term management of these patients even once the emergency is over, contributing to change care delivery and putting healthcare through modernization process.

The use of smartphone applications can significantly facilitate the communication and the sharing of information among patients, their families, and caring physicians. Prompt messaging through WhatsApp, social media (e.g., Instagram, Twitter, or Facebook), or the short message service lets patients to rapidly and directly contact their physicians, inquiring urgent questions, and exchanging information. These recommendations may help healthcare professionals provide optimal care to caregivers of epileptic children during the coronavirus pandemic.

\section{References}

1. Sharma A, Maxwell CR, Farmer J, Greene-Chandos D, LaFaver K, Benameur K. Initial experiences of US neurologists in practice during the COVID-19 pandemic via survey. Neurology. 2020;95(5):215-20. https://doi.org/10.1212/ wnl.0000000000009844 PMid:32439820

2. Brigo F, Bonavita S, Leocani L, Tedeschi G, Lavorgna L, Digita Technologies, Web and Social Media Study Group of the Italian Society of Neurology. Web and Social Media Study Group of the Italian Society of Neurology. Telemedicine and the challenge of epilepsy management at the time of COVID-19 pandemic. Epilepsy Behav. 2020;110:107164. https://doi.org/10.1016/j. yebeh.2020.107164

PMid:32480303

3. Klein BC, Busis NA. COVID-19 is catalyzing the adoption of teleneurology. Neurology. 2020;94(21):903-4. https://doi. org/10.1212/wnl.0000000000009494

PMid:32238505

4. French JA, Brodie MJ, Caraballo R, Devinsky O, Ding D, Jehi L, et al. Keeping people with epilepsy safe during the COVID19 pandemic. Neurology. 2020;94(23):1032-7. https://doi. org/10.1212/wnl.0000000000009632

PMid:32327490

5. Kuroda N. Epilepsy and COVID-19: Associations and important considerations. Epilepsy Behav. 2020;108:107122. https://doi. org/10.1016/j.yebeh.2020.107122

PMid:32361677

6. Francesco P, Plevin, David P, Nicholas S. Assessment and management of depression and anxiety in children and adolescents with epilepsy. Behav Neurol. 2019; 2;2019:2571368. PMid:31191736

7. GBD 2016 Epilepsy Collaborators. Global, regional, and 
national burden of epilepsy, 1990-2016: A systematic analysis for the Global Burden of Disease Study 2016. Lancet Neurol. 2019;18(4):357-75. https://doi.org/10.341 0/f.735346535.793561284

PMid:30773428

8. Kissani N, Lengané YT, Patterson V, Mesraoua B, Dawn E, Ozkara C, et al. Telemedicine in epilepsy: How can we improve care, teaching, and awareness? Epilepsy Behav. 2020;103(Pt A):106854. https://doi.org/10.1016/j.yebeh.2019.106854 PMid:31917142

9. Jernigan DB. Update public health response to the coronavirus disease 2019 outbreak United States, February 24, 2020 MMWR Morb Mortal Wkly Rep. 2020;69(8):216-9. https://doi. org/10.15585/mmwr.mm6908e1

PMid:32106216

10. Wrighta JH, Caudillba R. Remote treatment delivery in response to the COVID-19 pandemic. Psychother Psychosom. 2020;89(3):130-2.

PMid:32213775

11. Keesara S, Jonas A, Schulman K. COVID-19 and health care's digital revolution. N Engl J Med. 2020;382(23):e82. https://doi. org/10.1056/nejmp2005835

PMid:32240581

12. Huang S, Wu C, Jia Y, Li G, Zhu Z, Lu K, et al. COVID-19 outbreak: The impact of stress on seizures in patients with epilepsy. Epilepsia. 2020;61(9):1884-93. https://doi.org/10.1111/

\section{epi. 16635}

13. Fonseca E, Quintana M, Lallana S, Restrepo JL, Abraira L, Santamarina E, et al. Epilepsy in time of COVID-19: A surveybased study. Acta Neurol Scand. 2020;142(6):545-54. https:// doi.org/10.1111/ane.13335

PMid:32799337

14. Blanco EC, Manzanares I, Centeno M, Khawaja M, Betrán O, Donaire A, et al. Epilepsy and lockdown: A survey of patients normally attending a Spanish center. Acta Neurol Scand. 2021;143(2):206-9. https://doi.org/10.1111/ane.13354 PMid:32990951

15. Hao X, Zhou D, Li Z, Zeng G, Hao N, Li E, et al. Severe psychological distress among patients with epilepsy during the COVID-19 outbreak in Southwest China. Epilepsia. 2020;61(6):1166-73. https://doi.org/10.1111/epi.16544 PMid:32353184

16. Albert DV, Das RR, Acharya JN, Lee JW, Pollard JR, Punia V, et al. The impact of COVID-19 on epilepsy care: A survey of the american epilepsy society membership. Epilepsy Curr. 2020;20(5):316-24. https://doi.org/10.1177/1535759720956994 PMid:32942901

17. Miller WR, Von Gaudecker J, Tanner A, Buelow JM. Epilepsy self-management during a pandemic: Experiences of people with epilepsy. Epilepsy Behav. 2020;111:107238. https://doi. org/10.1016/j.yebeh.2020.107238

PMid:32593874 